\title{
The Decay and Fungal Succession of Apples with Bitter Rot Across a Vegetation Diversity Gradient
}

\author{
Phillip L. Martin, ${ }^{1}$ William L. King, ${ }^{2}$ Terrence H. Bell, ${ }^{2}$ and Kari A. Peter ${ }^{1, \dagger}$ \\ ${ }^{1}$ Department of Plant Pathology and Environmental Microbiology, Fruit Research and Extension Center, The Pennsylvania State \\ University, Biglerville, PA 17307 \\ ${ }^{2}$ Department of Plant Pathology and Environmental Microbiology, The Pennsylvania State University, University Park, PA 16802
}

Accepted for publication 6 September 2021.

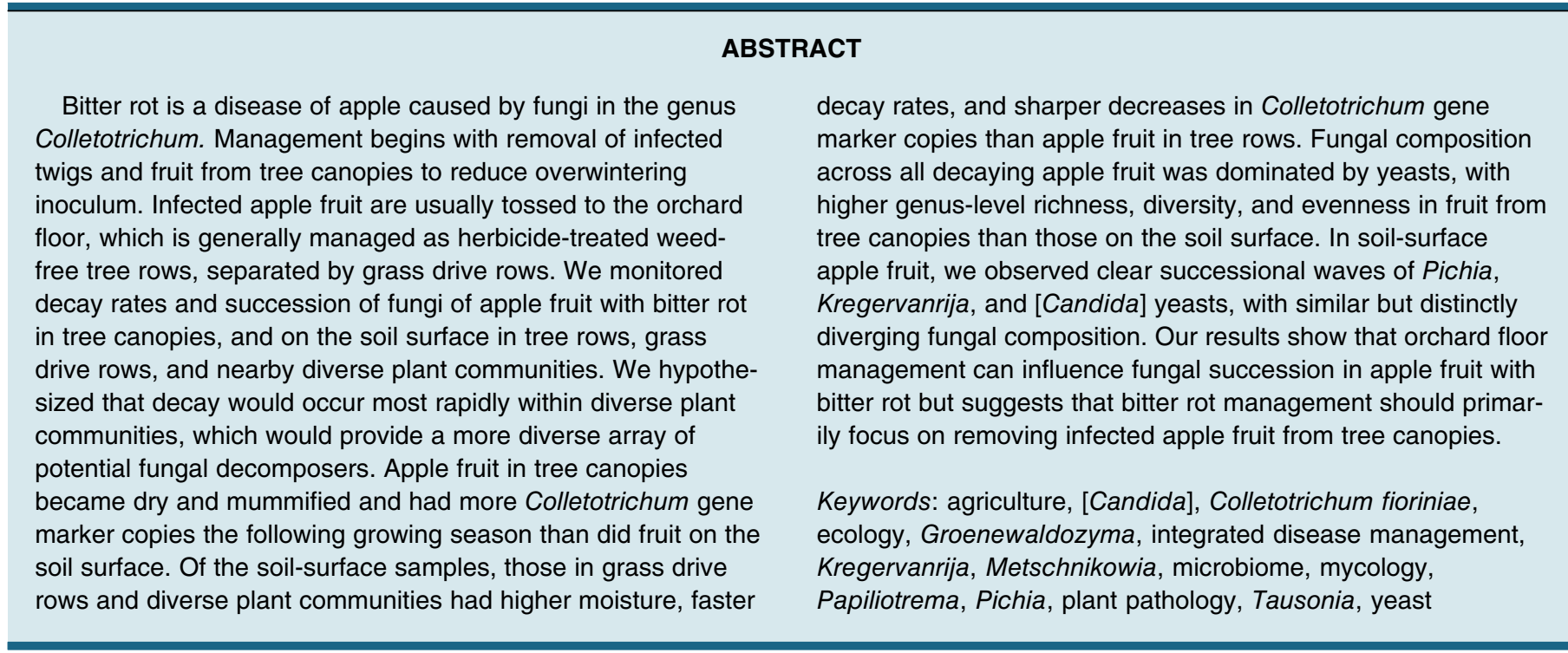

Apple is one of the most popular fruit of temperate regions worldwide (Ferree and Warrington 2003). In the Mid-Atlantic and Northeast regions of the United States, approximately 1 billion $\mathrm{kg}$ of apple fruit are produced annually, with a value of approximately \$500 million (USDA-NASS 2018). Numerous diseases challenge apple production, including apple scab, cedar apple rust, white rot, black rot, and bitter rot (Penn State University Extension 2020;

\section{Corresponding author: K. A. Peter; kap22@psu.edu}

Funding: This work was supported by the United States Department of AgricultureNational Institute of Food and Agriculture under project PEN04694 and accession number 1018736 and project PEN04651 and accession number 1016233; the Northeast Sustainable Agriculture Research and Education program under subaward number GNE16-180-32231; and a National Science Foundation Graduate Student Fellowship.

*The $\boldsymbol{e}$-Xtra logo stands for "electronic extra" and indicates that supplementary materials are published online.

The author(s) declare no conflict of interest.

(C) 2022 The American Phytopathological Society
Sutton et al. 2014). Of these diseases, bitter rot has emerged as one of the most challenging diseases on susceptible cultivars (Martin et al. 2021). Bitter rot is caused by several species in the Colletotrichum gloeosporioides and $C$. acutatum species complexes (SC), of which $C$. fioriniae of the $C$. acutatum $\mathrm{SC}$ is the most common in the Mid-Atlantic region (Martin et al. 2021). These species also cause disease on a wide range of other crops, including peach, grape, blueberry, cranberry, and strawberry (Dowling et al. 2020).

In general, recommendations have been to either remove rotten apple fruit from the orchard or to toss them to the orchard floor to decay, because pathogens can overwinter in mummified fruit in the tree canopy (Penn State University Extension 2020; Sutton et al. 2014). Although removing rotten fruit from orchards would completely eliminate them as inoculum sources, most rotten apple fruit are simply tossed to the orchard floor, due to time and labor costs (personal observation). Orchard floors are usually kept weed free under the tree rows through herbicide applications in order to produce faster tree growth and higher yields, with a mowed grass sod in the drive rows (Penn State University Extension 2020). It has been hypothesized that infected apple fruit should decay faster in more "biologically active" grass strips, because higher carbon 
inputs and faster nutrient cycling is expected in grass sod relative to herbicide-treated tree rows, which have a bare soil surface (Rosenberger and Cox 2016).

A substantial body of evidence shows that the Colletotrichum spp. that cause bitter rot do not persist long in biologically active soil. In early bitter rot research, Burrill (1907) showed that mummified apple fruit that were kept dry would resume spore production several years later when rehydrated. Colletotrichum spores were isolated from infected apple fruit that mummified and overwintered in the tree canopy, whereas they could not be isolated from infected fruit that overwintered on the soil underneath the trees (Burrill 1907). The tree rows in the Burrill (1907) research were not treated with herbicides, because weed control in that era was primarily with tillage. When Colletotrichum spores were mixed with soil and that soil was used to inoculate apple fruit, no bitter rot developed if the spores were added to the soil more than $72 \mathrm{~h}$ before inoculation, indicating that spores do not survive more than 3 days in moist, well-aerated soil (Burrill 1907). In research on strawberry, Colletotrichum conidia survived up to a year in autoclaved soil but saw a $95 \%$ reduction in viability in moist, untreated soil after a few days (Freeman et al. 2002). The Colletotrichum spp. that cause bitter rot survive best in plant material, especially in coarsetextured, slower-decaying plant material, with the longest survival times under conditions of low biological activity such as cool temperatures, low moisture, or treatment with soil fumigants (Eastburn and Gubler 1990, 1992; Freeman et al. 2002; Kang et al. 2009; Parikka and Lemmetty 2009; Parikka et al. 2006; UreñaPadilla et al. 2001).

Moving rotten apple fruit out of herbicide-treated tree rows to the grass strips would be less costly than completely removing them from the orchard. However, before such a practice could be recommended to growers, it must be demonstrated that this would result in faster decay of the rotten apple fruit, with a corresponding reduction in the amount of inoculum being carried over to the next season. The objective of this research was to track the decay and succession of apple-associated fungi on apple fruit infected with bitter rot on the orchard floor, comparing the weed-free herbicidetreated tree rows with the grass drive rows and with a nearby diverse plant community. Because we expected available fungal diversity (i.e., potential decomposers) to scale with plant diversity (Francioli et al. 2021; Nguyen et al. 2016), we hypothesized that decay would occur most quickly within the diverse plant community and least quickly within herbicide-treated rows.

\section{MATERIALS AND METHODS}

Treatments. These studies occurred at Penn State's Fruit Research and Extension Center in Biglerville PA, U.S.A. The experimental orchard consisted of repeating blocks of five cultivars on semidwarfing rootstock that were planted in 1985. The blocks were planted in a 5-by-16 grid, with grass drive rows separating the blocks. The orchard floor consisted of weed-free bare soil beneath the trees, maintained by regular applications of herbicides, with grassed drive rows between the blocks that were maintained by mowing. A nearby pollinator block was planted in 2011, containing a diverse mixture of flowering broadleaf plants and grasses, and was maintained by annual or biannual late summer mowing. Both orchard and pollinator block had Arendtsville gravely loam soils, with the pollinator block on the edge of a transition to Readington silt loam.

Honeycrisp apple fruit with bitter rot were placed at harvest on the orchard floor in a weed- and grass-free tree row, the adjacent grass drive row, and a nearby diverse plant community that was planted as pollinator habitat (Fig. 1). The experiment was set up as a completely randomized design, with three replications at each treatment location (weed-free tree row, grass drive row, and diverse plant plot). The apple fruit were placed in a grid, leaving fruit at least $30 \mathrm{~cm}$ apart. Each apple was weighed at placement and its location recorded. Apple fruit infected with bitter rot were either wound inoculated with $C$. fioriniae mycelia or were naturally infected and came from trees that had been inoculated with C. fioriniae conidia early in the summer. For the December sample in 2018 and for every sample collection time in 2019 to 2020, fruit were also collected from the tree canopy (Fig. 2).

Soil sampling. Soil samples were randomly collected from each treatment location and tested by the Ag Analytical Services Lab at Penn State University for $\mathrm{pH}$ (1:1 water); acidity (Mehlich buffer); Mehlich 3 extractable $\mathrm{P}, \mathrm{K}, \mathrm{Ca}, \mathrm{Mg}, \mathrm{Zn}, \mathrm{Cu}$, and $\mathrm{S}$; cation exchange capacity (by summation); and organic matter. Six soil samples were collected from each treatment, and each sample was the combination of 10 soil cores taken to a depth of approximately $20 \mathrm{~cm}$. Samples were dried in a drying oven at $50^{\circ} \mathrm{C}$ for 2 days and sent to the lab for testing.

Sample collection. Each sample consisted of four apple fruit, and samples were collected and weighed once a month starting from the initial placement in early October, unless the ground was frozen. Apple fruit with bitter rot were placed in the orchard on 4 October 2018, and sample collections were taken on the placement date and on 26 October 2018, 6 December 2018, and 19 March 2019. The fruit were largely degraded by late May and no collection was taken that month. Apple fruit with bitter rot were again placed out in the orchard on 3 October 2019 and samples taken on the placement date and on 30 October 2019, 6 December 2019, 31 January 2020, 6 April 2020, and 27 May 2020.

The apple fruit were placed in a Waring Laboratory blender (Dynamics Corp. of America, New Hartford, CT, U.S.A.) and blended to slurry. Up to $400 \mathrm{ml}$ of water was added to the sample, as needed, for blending. Approximately $40 \mathrm{ml}$ of the sample was placed in labeled Eppendorf tubes and stored in a $-20^{\circ} \mathrm{C}$ freezer for future DNA extraction. Approximately $150 \mathrm{~g}$ of the sample was put on a paper plate, weighed, placed in a drying oven for several days until dry, and weighed again. The percent dry matter of the sample was calculated from the wet and dry sample weights, and the corrected percent dry matter of the sampled fruit was calculated based on the weight of the four fruit and the weight of the added water.

Spore production from samples. For the first two collections in 2018, four apple fruit from each replication were collected, rinsed in warm water, gently brushed to remove existing surface spores, and placed in a closed plastic tub with moist paper towel to maintain high humidity. The fruit were incubated at room temperature $\left(20\right.$ to $\left.23^{\circ} \mathrm{C}\right)$ for 8 days to stimulate fresh spore production. After incubation, the apple fruit were washed with water in a beaker and brushed to remove the spores on the apple surface; the wash water was transferred to 225-ml centrifuge tubes, centrifuged, and decanted; and the pelleted spores were stored at $-20^{\circ} \mathrm{C}$ until DNA extraction.

DNA extraction. Approximately $50 \mathrm{mg}$ (2018 samples) or $25 \mathrm{mg}$ (2019 samples) of equivalent dry mass material was added to NucleoSpin Soil DNA extraction kit lysis tubes (Macherey Nagel, Bethlehem, PA, U.S.A.). Because of high liquid content in some samples, all samples were centrifuged for $10 \mathrm{~min}$ at $16,000 \times g$ and the supernatant decanted to make room for lysis reagents.

DNA extraction was performed with the NucleoSpin Soil kit with the following modifications. For step 1, $500 \mathrm{ml}$ of buffer SL2 was pipetted into the centrifuge tube and, after addition of Enhancer SX in step 2, the sample was lysed by using a Macherey Nagel bead tube holder attached to a Vortex Genie (Scientific Industries, 
Bohemia NY, U.S.A.) at maximum speed for $12 \mathrm{~min}$. The rest of the DNA extraction followed protocol, which was finished by a two-step DNA elution in $50 \mu \mathrm{l}$ of buffer SE for a total of $100 \mu \mathrm{l}$ of purified DNA. A negative control (no initial sample) was included in every DNA extraction to check for contaminated reagents.

Quantification with quantitative PCR. C. fioriniae DNA was quantified using the $C$. acutatum SC (which includes $C$. fioriniae)specific methods of Debode et al. (2009), as used by Martin and Peter (2021). Briefly, it is a TaqMan (Thermo Fisher Scientific, Waltham MA, U.S.A.)-based assay that is specific to the $C$. acutatum SC. Primers were synthesized by Integrated DNA Technologies (Skokie, IL, U.S.A.), and the PCR plates and optically clear strip caps were from VWR (Radnor, PA, U.S.A.). The assay was run on a Bio-Rad C1000 thermocycler with the CFX96 detection system (Bio-Rad Laboratories Inc., Hercules CA, U.S.A.) to 40 cycles. A standard curve was created by counting three separate suspensions of $C$. fioriniae spores with a hemocytometer, taking a calculated $1 \times 10^{7}$ spores from each suspension, and extracting DNA using the NucleoSpin Soil kit described above. The three samples were analyzed with the quantitative PCR (qPCR) assay for variation, then combined into a single sample and serially diluted 10-fold from $1 \times$ $10^{7}$ to $1 \times 10^{3}$ conidia equivalents. DNA standards of $1 \times 10^{7}, 1 \times$ $10^{6}, 1 \times 10^{4}$, and $1 \times 10^{3}$ were added to each qPCR run as an internal standard to equate cycle number to conidia number. All samples were run in triplicate and averaged.

Baseline correction and quantification thresholds for qPCR were set automatically by the Bio-Rad software and conidia equivalents were automatically calculated by the software based on the cycle quantification value and the internal standard curve. Results were exported to an Excel (Microsoft, Redmond, WA, U.S.A.) spreadsheet for summarizing and graphing. All qPCR data were normalized to starting tissue weight.

Fungal profiling through amplicon sequencing. To characterize fungal composition, we carried out amplicon sequencing targeting the fungal internal transcribed spacer (ITS) 1 region using the ITS1F (Gardes and Bruns 1993) and 58A2R (Martin and Rygiewicz 2005) primer pair with linker and adapter regions for Illumina sequencing (ITS1F-Illu 5'-TCGTCGGCAGCGTCAGATGTGTAT AAGAGACAGCTTGGTCATTTAGAGGAAGTAA-3' and 58A2 R-Illu 5'-GTCTCGTGGGCTCGGAGATGTGTATAAGAGACA GCTGCGTTCTTCATCGAT-3'). Initial amplicons with Illumina overhangs were generated on an Eppendorf Mastercycler (Eppendorf North America, Enfield, CT, U.S.A.). PCR reagents were Thermo Fisher DreamTaq Green $2 \times$ master mix, $0.5 \mu \mathrm{M}$ primers, and $1 \mu \mathrm{l}$ of template DNA in a 20- $\mu$ l reaction. PCR conditions were $94^{\circ} \mathrm{C}$ for $5 \mathrm{~min}$; then, 35 cycles of $94^{\circ} \mathrm{C}$ for $30 \mathrm{~s}, 45^{\circ} \mathrm{C}$ for $30 \mathrm{~s}$, and $72^{\circ} \mathrm{C}$ for $45 \mathrm{~s}$; with a final elongation for $5 \mathrm{~min}$. Amplicons were sent to The Huck Institutes Genomics Core Facility (Pennsylvania State University) for indexing and sequencing on the Illumina MiSeq platform $(2 \times 250 \mathrm{bp})$.

Amplicon sequencing data analysis. Raw demultiplexed fungal ITS gene data were processed using the Quantitative Insights into Microbial Ecology pipeline (QIIME 2, version 2020.2.0) (Bolyen et al. 2019). Briefly, paired-end ITS sequences were imported, trimmed using ITSxpress (Rivers et al. 2018), and denoised using DADA2 (Callahan et al. 2016). Taxonomy was classified using the classify-sklearn qiime feature classifier against the UNITE database (version 8.2) (Abarenkov et al. 2020) at the single-nucleotide threshold (amplicon sequence variant [ASV]), using the default confidence threshold of $70 \%$. ASVs with less than 41 counts were removed
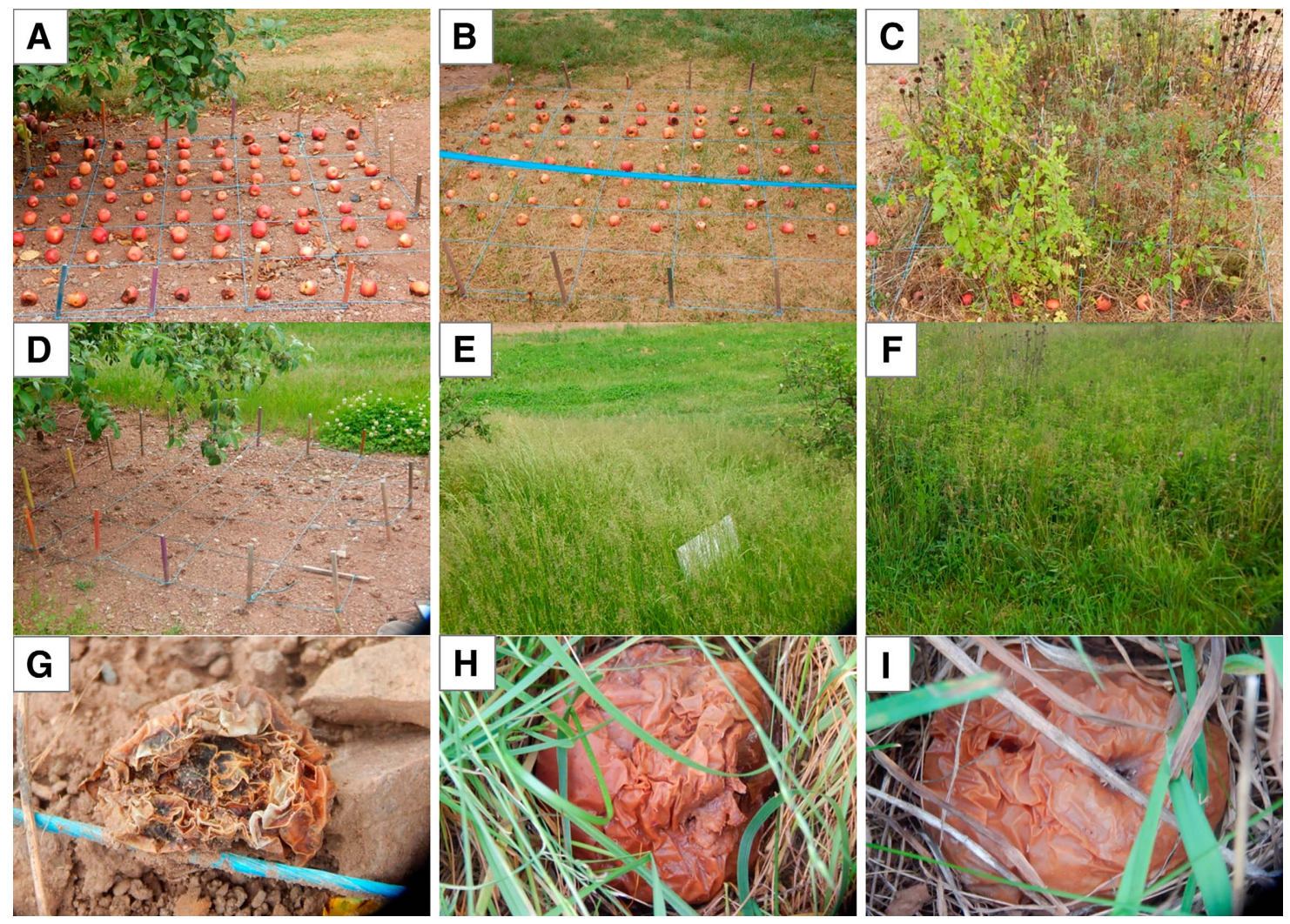

Fig. 1. Example photographs of the treatments. A to $\mathbf{C}$, Herbicide-treated tree row, grass drive row, and diverse plant mix treatments, respectively, in October. D to F, Herbicide-treated tree row, grass drive row, and diverse plant mix treatments, respectively, the following May. G to I, Example photos of apple fruit from $D$ to $F$, respectively. Treatment plots were not treated with herbicides or mowed during the experiment. 
$(0.001 \%)$ and rarefied to 10,693 sequences/sample. Data were summarized at different taxonomic levels using the qiime taxa barplot command. The ITS1 region of the most common ASVs in the "unidentified Ascomycota" category were individually BLAST searched in GenBank. Four ASVs were identified as [Candida], which is a designation given to yeast that were historically categorized in the Candida genus but are now awaiting to be formally renamed (NIH 2021), and six ASVs were identified as most similar to Metschnikowia spp. To differentiate them from the Metschnikowia spp. that were identified by the UNITE database, these ASVs were denoted as [Metschnikowia] (manually identified ASVs and applicable notes in Supplementary Materials). The remaining ASVs that could not be identified to genus were grouped by the next highest taxonomic level they could be identified as, such as "Ascomycota", "Fungi", and "Remaining" sequences. The fungal genera were further grouped into the morphological groups of either yeast or filamentous fungi based on literature searches of each genus. The raw sequence reads were deposited in the NCBI database and are available under BioProject accession PRJNA732466.

Statistical analysis. Dry matter loss of apple fruit by treatment was compared across all the collection time points (not including the starting samples) by subtracting the average of the three treatments from each treatment and comparing the differences with analysis of variance (ANOVA) followed by means separation with

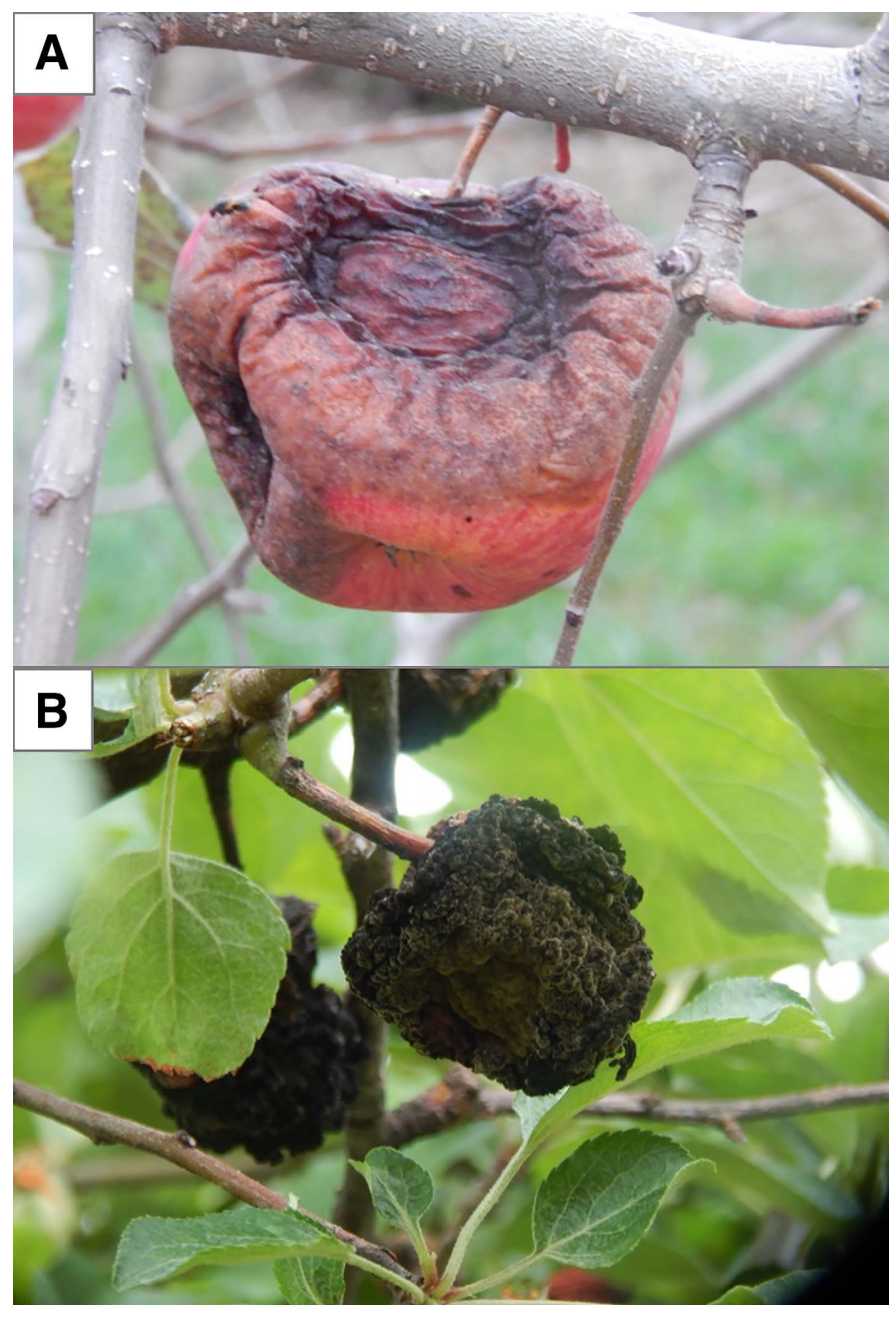

Fig. 2. Apple fruit in the tree canopy were also sampled to compare with the soil-surface treatments. A, Apple fruit with bitter rot in the tree canopy in October. B, Mummified apple in the tree canopy the following May. a Tukey's honestly significant difference (HSD) test, using the Agricola package (De Mendiburu 2009) in R (R Core Team 2021). The $\log _{10}$-transformed $C$. acutatum SC conidia equivalents and percent moisture of the treatments were compared across collection time points using the same method. Soil organic matter in each treatment was compared with ANOVA followed by means separation with a Tukey's HSD test. Processed sequence data were imported into the R statistical environment. Genus-level $\alpha$-diversity indexes of Shannon diversity and Pielou evenness were calculated using the microbiome package (Lahti et al. 2017). Tree-sample $\alpha$-diversity indices were compared with those from the soil using both $t$ tests and Kruskal-Wallis tests. $\beta$ Diversity was visualized with a nonmetric multidimensional scaling analysis (nMDS). An overall nMDS ordination was generated using the Phyloseq package (McMurdie and Holmes 2013). To visualize temporal patterns using centroids, an nMDS ordination for each season was generated using the metaMDS, ordiplot, and ordibar functions in the vegan package (Oksanen et al. 2020). Patterns elucidated by the nMDS ordination were statistically tested with the Adonis function (999 permutations) in the vegan package. Graphs were created in R or Excel and edited in Powerpoint (Microsoft).

\section{RESULTS}

Soil sampling. The mineral nutrients of phosphorus and potassium did not vary significantly between treatments, while magnesium and sulfur were lowest in the tree rows and highest in the diverse plant mix and calcium, zinc, and copper were highest in the tree rows and grass drive rows and lowest in the diverse plant mix (Raw data, figures, and statistics in Supplementary Tables S2 and S3 and Supplementary Fig. S1). Soil pH averaged 6.7 in both herbicide-treated tree rows and grass drive rows, which was significantly higher than the 5.8 in the diverse plant mix $(P<0.001)$. Percent organic matter averaged $3.1 \%$ in both the grass drive row and diverse plant mix, which was significantly higher than the $1.5 \%$ in the tree rows $(P<0.001)$.

Rate of decay. Percent dry matter of the samples across both years showed an initial rapid decrease in the fall after apple fruit were placed on the ground, with slower decreases over the colder winter months (Fig. 3A and D). Although the dry matter of samples from the different treatments did not diverge widely, when evaluated across all sampling times, samples in the herbicide-treated tree rows had approximately $9.5 \%$ more dry matter than samples in the grass drive rows and diverse plant mix (Fig. 3G, with exact pairwise $P$ values in Supplementary Table S1).

Quantification with qPCR. qPCR tests of DNA extracted from the 2018-to-2019 samples showed little decrease in total C. acutatum SC gene marker copies in decaying apple fruit from October to March (Fig. 3B). The 2019-to-2020 samples included samples from apple fruit with bitter rot in the tree canopy, which showed increases in $C$. acutatum SC gene marker copies as the rot spread through the fruit, with subsequent decreases from February to May (Fig. 3E). The other samples showed decreases in total C. acutatum SC gene marker copies in the period from February to May (Fig. 3E). Visual observations of the decayed apple fruit revealed no orange spore masses indicative of Colletotrichum spp. Comparisons of the differences between treatments across sample times showed that apple fruit in the herbicide-treated tree rows had the most $C$. acutatum SC gene marker copies, followed by fruit in the diverse plant mix and grass drive rows (Fig. $3 \mathrm{H}$, with exact pairwise $P$ values in Supplementary Table S1).

Moisture content of samples. Moisture of apple fruit in the grass drive rows and diverse plant mix rose from initial moistures of 85 to $87 \%$ in October to 93 to $95 \%$ by the next spring, whereas 
the moisture in the fruit in the herbicide-treated tree rows and the tree canopies over the same time period dropped as low as 15 to $20 \%$ (Fig. 3C and F). Visually, apple fruit in the grass drive row and diverse plant mix were soft and moist, whereas those in herbicide-treated tree rows and tree canopies were relatively shriveled and dry (Figs. 1 and 2). Comparisons of the differences between treatments across sample times showed that apple fruit in the herbicide-treated tree rows had significantly less moisture than fruit in the grass drive rows and diverse plant mix (Fig. 3I, with exact pairwise $P$ values in Supplementary Table S1).

Spore production from samples. Visually, no orange Colletotrichum spore masses were observed on any of the apple fruit, and white yeast was growing on many of the bitter rot lesions. qPCR of DNA extracted from the spores showed that $C$. acutatum SC gene marker copies were $>100$-fold lower than in the whole fruit (Supplementary Fig. S2A). Amplicon sequencing data did not detect any $C$. acutatum SC in the spore samples which, instead, consisted mostly of Pichia and Kregervanrija yeasts (Supplementary Fig. S2B). Samples of the whole apple fruit showed that Colletotrichum represented $23 \%$ of all fungal reads, with Pichia, Kregervanrija, and a diversity of other yeasts and filamentous fungi making up the rest (Supplementary Fig. S2B).

Fungal community profiling. Fungal composition in the initial samples showed a high relative abundance of sequences assigned to

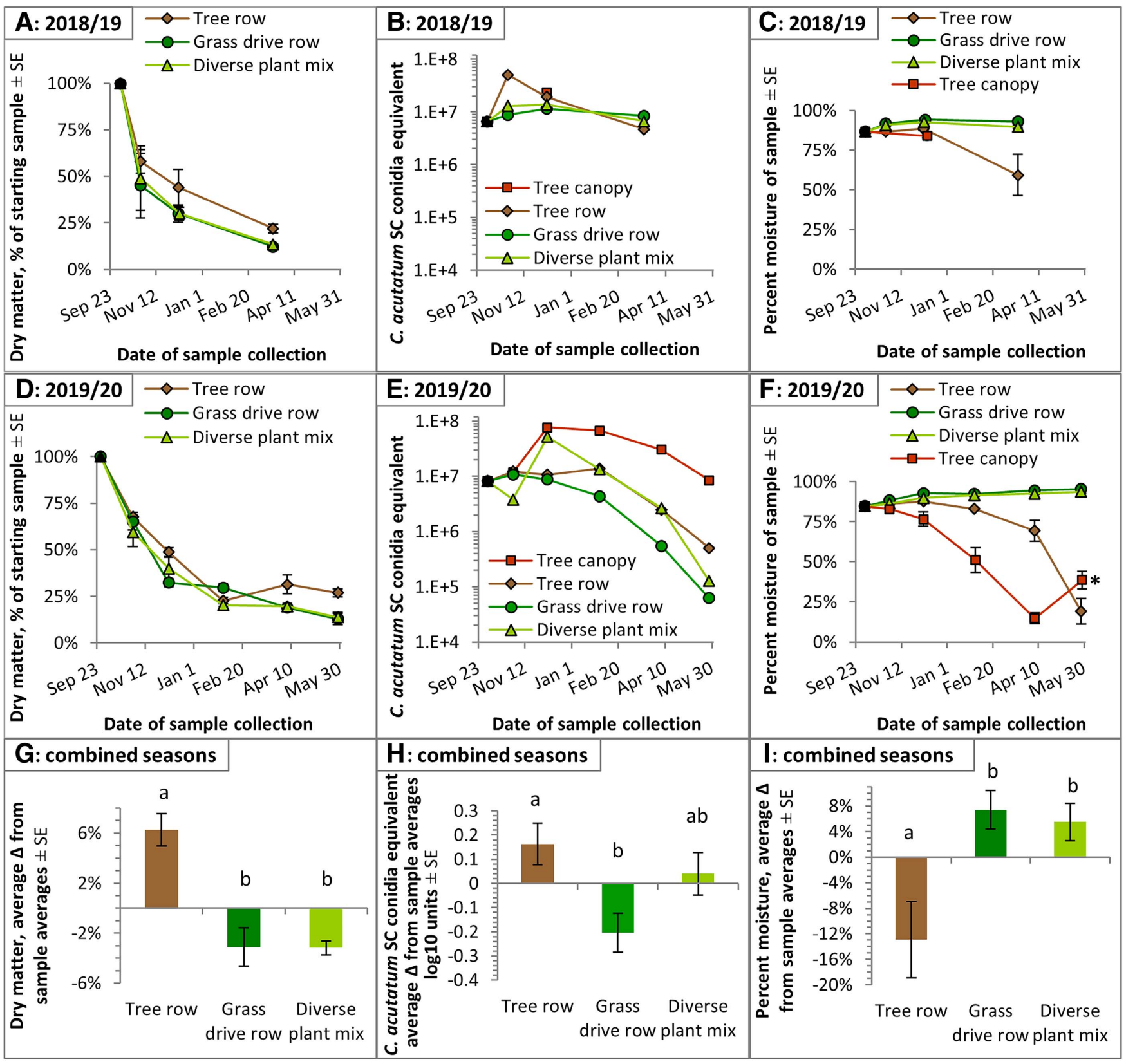

Fig. 3. Decay and loss of dry matter, results of quantitative PCR tests of Colletotrichum acutatum species complex DNA, and percent moisture of apple samples collected a various time points after placement on the ground in herbicide-treated tree rows, grass drive rows, and a diverse plant mix, or were allowed to remain hanging in the tree canopy. Error bars are \pm one standard error of the mean. A to C, Fall 2018 to spring 2019. D to F, Fall 2019 to spring 2020. G to I, Average differences of each treatment from the average of the three treatments at each collection time point across both 2018-19 and 2019-20 seasons, not including the starting samples or the tree canopy samples. Different letters indicate statistical significance for $\mathrm{G}(P<0.0001), \mathrm{H}(P<0.05)$, and I $(P<0.01)$ as determined by analysis of variance with a Tukey's honestly significant difference test. The data point denoted by an asterisk in panel $\mathrm{F}$ was from a sample collected 1 day later than the other samples, after a light rain. 
the Colletotrichum genus, with subsequent decreases in Colletotrichum over time (Fig. 4A and B). Colletotrichum was not observed through amplicon sequencing in spring-collected soil-surface treatments, whereas Colletotrichum persisted into the spring in tree canopy samples (Fig. 4A and B). Most nonColletotrichum genera were yeasts (Fig. 4C and D). Apple fruit in tree canopies contained a diverse array of yeasts, in which Pichia, Papiliotrema, and Metschnikowia were well represented (Fig. 4), while we observed clear and dominant successional waves of Pichia, Kregervanrija, and [Candida] yeasts in soil-surface apple fruit (Fig. 4; Supplementary Fig. S3).

The tree canopy samples had more richness, diversity, and evenness of fungal genera than the soil-surface samples, with all

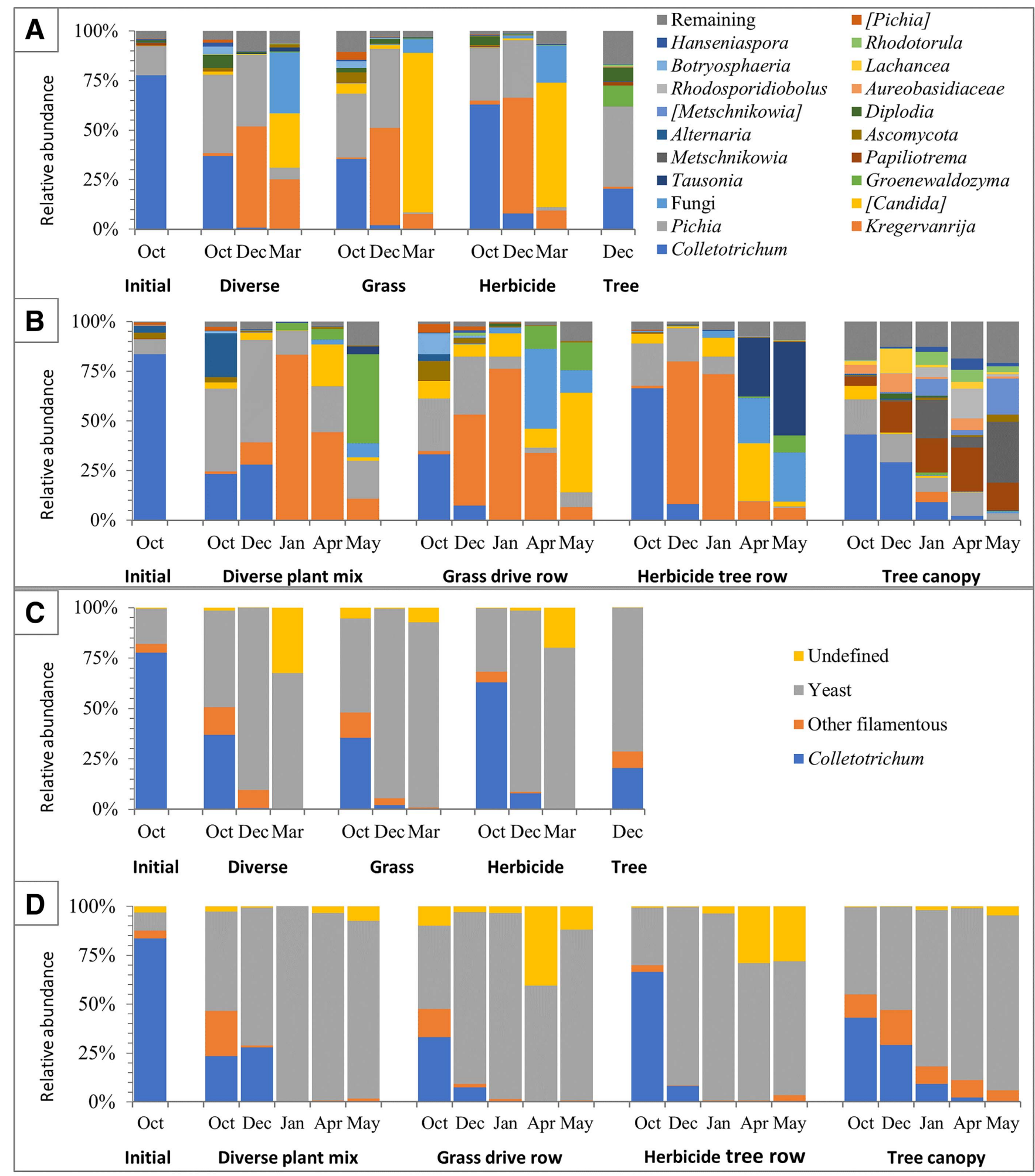

Fig. 4. Most common fungal genera and morphological groups of decaying apple as identified with amplicon sequencing data Most common genera in A, 2018-19 and B, 2019-20. C and D, Identical to A and B but with morphological groups of filamentous and yeast fungi instead of genera. Filamentous fungus Colletotrichum is displayed separately because it is the cause of the bitter rot which initiated the decay process. 
comparisons significant at $P<0.0001$ (Fig. 5A). An nMDS analysis showed that fungal composition in soil-surface apple fruit (combined treatments) diverged strongly from fungal composition in tree canopy fruit (Fig. 5B). The overall comparison and each pairwise comparison were all significant at $P<0.01$ as determined with permutational multivariate analysis of variance.

Of the soil-surface samples, the herbicide-treated tree row and diverse plant mix samples were the most widely divergent, with the grass drive row samples intermediate between those two (Fig. 6). Not including the initial samples, comparisons in the 2018-19 season were not different at $P=0.7$, whereas the overall comparison of 2019-20 samples were different at $P=0.05$, herbicide versus diverse samples at $P=0.02$, herbicide versus grass samples at $P=0.055$, and diverse versus grass samples at $P=0.5$.

\section{DISCUSSION}

Bitter rot is a significant source of apple losses in warm and humid growing regions. Reducing the amount of infectious propagules that survive the winter is the first step in reducing losses to bitter rot. Here, we observed a stronger persistence of Colletotrichum absolute (qPCR) and relative abundance throughout the winter in apple fruit in tree canopies than in fruit on the soil surface. Within soil-surface treatments, apple fruit with bitter rot in herbicide-treated tree rows
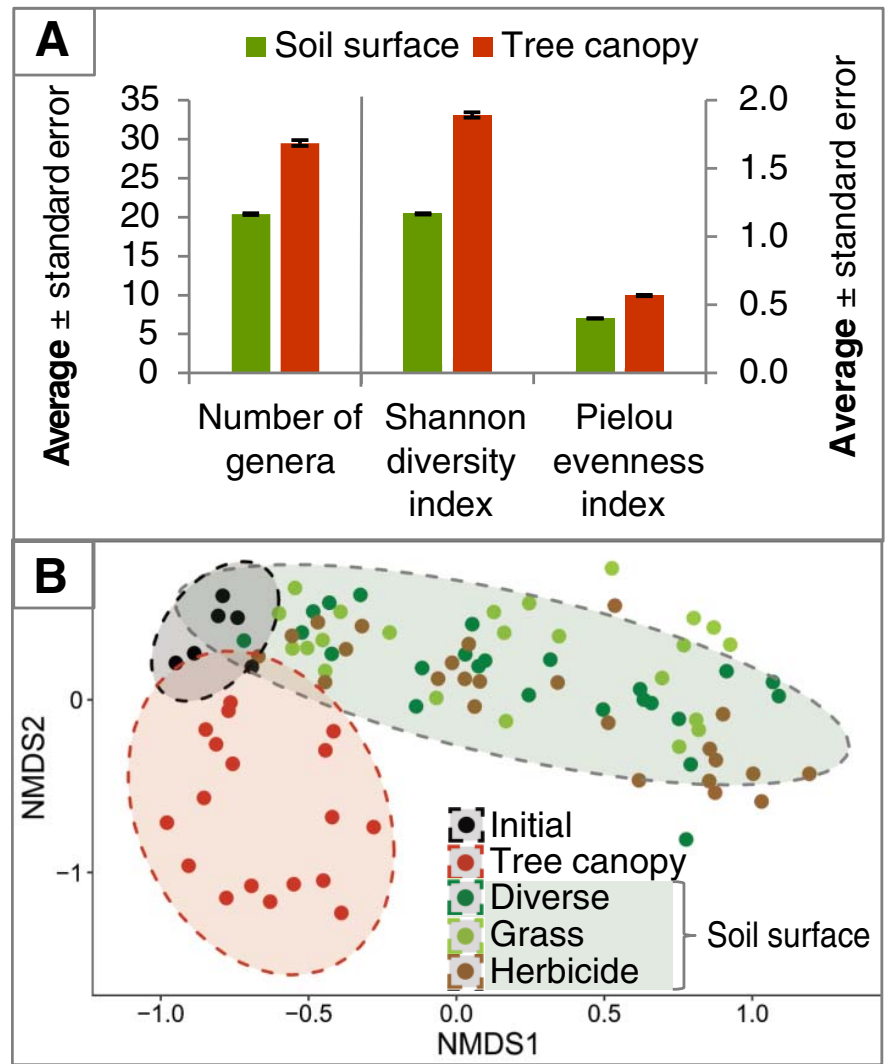

Fig. 5. Overall comparisons of fungal community diversity and community composition of samples on the soil surface and those in the tree canopy, combined across two seasons. A, Comparisons of the number of fungal genera (left axis) and the Shannon diversity index and Pielou evenness index of fungal genera (right axis). Each diversity comparison was significant at $P<0.0001$ per both $t$ tests and Kruskal-Wallis tests. B, Nonmetric multidimensional scaling (NMDS) of the initial fungal communities and subsequent communities on soil surfaces and tree canopies. Each pairwise comparison was significant at $P<0.001$. decayed slightly slower than fruit in grass drive rows or diverse plant mixes. Apple fruit in tree canopies and, to a much lesser extent, fruit in tree rows, were mummified and partially dried out. Lower moisture appeared to be the biggest reason those fruit degraded slower than the ones in the grass drive row or diverse plant mix.

We demonstrated dramatic decreases in C. fioriniae DNA as the apple fruit decayed, as was expected, but also showed that fruit on the ground the following spring still contained $C$. fioriniae DNA, albeit at concentrations over an order of magnitude lower than in the fall. Whether this $C$. fioriniae DNA came from $C$. fioriniae that was still alive, or whether successional microbes had outcompeted and killed $C$. fioriniae and the DNA was simply residual DNA that had not yet degraded, is not known. Given the abundance of $C$. fioriniae detected in spore traps in the spring (Martin and Peter 2021), it is possible that some of the $C$. fioriniae DNA detected in the decayed apple fruit collected in the spring was not from the apple itself but splashed onto the apple surface from above.

The lack of Colletotrichum spore production on the surface of apple fruit retrieved from the soil surface appeared to be because the moist conditions were optimal for yeasts, which outcompeted any remaining Colletotrichum in terms of spore production. Saprophytic bacteria likely also played a significant role in outcompeting Colletotrichum. The C. acutatum and C. gloeosporioides SCs are primarily plant pathogens and endophytes and are generally poor

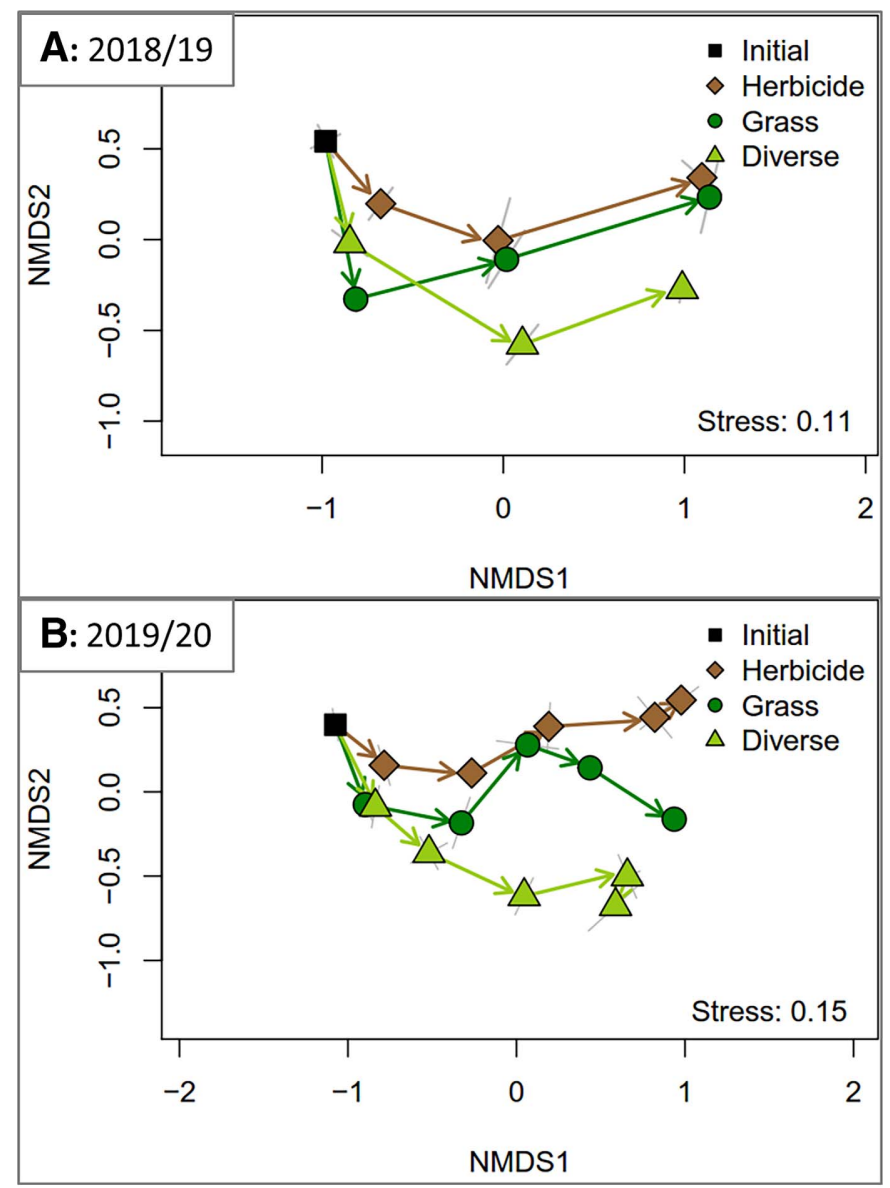

Fig. 6. Nonmetric multidimensional scaling (NMDS) analysis of fungal communities of soil-surface treatments, showing progression through time. Each point is the centroid of three replicates. A, For 2018-19 season, overall differences were not significant at $P=0.7$. B, For 2019-20 season, overall differences were significant at $P=0.05$. 
saprophytes (Damm et al. 2012; Martin and Peter 2021; Weir et al. 2012). It appears that these Colletotrichum spp. persist in dead plant material only if conditions are not optimal for competing saprophytes.

Even if viable Colletotrichum spores are produced on apple fruit on soil surfaces, the $C$. acutatum SC almost exclusively produces asexual conidia that are rain-splash dispersed (Peres et al. 2005), and it is unlikely that conidia would splash up into the tree canopy. However, the $C$. gloeosporioides SC also produces air-dispersed ascospores, which could be more of a problem. The key take-home message for apple growers is that apple fruit with bitter rot should be removed from the tree canopy and tossed on the ground to decay. Although apple fruit in the grass drive row decay slightly faster than those in the herbicide-treated tree row, we do not have evidence that fruit in the tree row are sources of inoculum. This of course could vary in orchards based on soil-surface conditions and the species of Colletotrichum causing the bitter rot.

Initially, fungal composition was dominated by Colletotrichum spp. The remaining fungi in the initial samples would have been mostly on the apple surface, because those fruit were only starting to decay at that point. Across all samples, the fungi that succeeded Colletotrichum were primarily various genera of yeasts, which grow well in conditions with abundant soluble sugars such as mature fruit (Doores 1983). Yeasts rarely cause plant diseases and are generally considered beneficial (Droby et al. 2009).

The Pichia yeasts that formed the first successional wave likely came from the fruit surface, because Pichia was already present on apple fruit before they were placed on the soil surface. The Kregervanrija yeasts, which formed a dominant second successional wave in the samples on the soil surface, were largely absent from initial samples or from samples in the tree canopy, suggesting that they might have come from the soil surface. The [Candida] yeasts are a kind of catch-all temporary genus that was created after DNA sequencing showed that the Candida genus as previously defined was incorrect (NIH 2021), and all the rest of the species that were now excluded from this genus were placed into [Candida] until they could be sorted out. Because of this, we are somewhat limited in the conclusions that we can draw from this third [Candida] successional wave. The final successional wave of "other genera" in the soil-surface samples included a fair amount of undefined fungi that likely include unculturable soil fungi.

The low organic matter in the soil samples from the tree row makes sense, considering it did not receive carbon inputs from a grass sod for over 30 years. Lower organic matter indicates lower microbial activity, which could have affected the apple decay rate. The regular applications of pesticides to the tree row might also have had an effect on microbial activity (Riedo et al. 2021).

Inoculum diversity may also have influenced fungal succession. A diverse plant mix is likely to support a diverse bank of fungal saprophytes (Francioli et al. 2021), which could lead to higher function through (i) niche complementarity (i.e., different fungi can perform different parts of the decomposition process) or (ii) selection effects (i.e., higher potential of selecting a top performing decomposer). Fungi from the tree phyllosphere can play important roles in leaf litter decomposition (Osono 2006), with rapid fungal succession as the litter decomposes (Voř́ršková and Baldrian 2013). We should note that our diverse plant mix was not spatially intermixed with the grass drive rows and herbicide-treated tree rows; therefore, we cannot rule out the possibility that differences with the other treatments was due to spatial variation instead of plant diversity.

The vast majority of studies looking at the decay of vegetation on soil surfaces have focused on the effect that decaying vegetation has on soil properties and plant growth rather than the effect that soil properties and plant communities have on decay rates (Atucha et al. 2011; Culumber et al. 2019). A study looking at the decomposition of understory plant residues in tree rows that were mulched with pine bark or pea straw versus those with a bare-soil herbicide strip found that decomposition was fastest on the bare soil, or on the soil underneath the mulch and straw (Tutua et al. 2002). This was attributed to rapid drying on the surface of the mulch and straw, whereas plant residue on the soil surface retained higher moisture. In our case, the grass and diverse plant communities grew up over the rotten apple fruit, protected them from wind, and prevented them from drying out. The thick sward of grass also seemed to have an insulating effect that kept those fruit from freezing as soon as those exposed on bare soil (personal observation).

In conclusion, absolute and relative amounts of $C$. fioriniae DNA were low in apple fruit with bitter rot on the soil surface, while fruit that remained in the tree canopy retained higher levels of C. fioriniae DNA and are likely sources of spores the following season. The successional fungi that move in after bitter rot starts the decay process are mostly yeasts. There were significant and consistent differences in fungal succession between apple fruit with bitter rot on the ground in herbicide-treated tree rows, in grass drive rows, and in a nearby diverse plant mix, suggesting that orchard floor management influences microbially driven processes on the soil surface.

\section{ACKNOWLEDGMENTS}

We thank T. Krawczyk for help extracting DNA and performing $\mathrm{qPCR}$ and $\mathrm{B}$. Lehman for help in performing $\mathrm{qPCR}$ and setting up the weather monitor.

\section{LITERATURE CITED}

Abarenkov, K., Zirk, A., Piirmann, T., Pöhönen, R., Ivanov, F., Nilsson, R. H., et al. 2020. UNITE QIIME release for Fungi. Version 04.02.2020. UNITE Community, London, U.K.

Atucha, A., Merwin, I. A., and Brown, M. G. 2011. Long-term effects of four groundcover management systems in an apple orchard. HortScience 46:1176-1183.

Bolyen, E., Rideout, J. R., Dillon, M. R., Bokulich, N. A., Abnet, C. C., Al-Ghalith, G. A., et al. 2019. Reproducible, interactive, scalable and extensible microbiome data science using QIIME 2. Nat. Biotechnol. 37: 852-857.

Burrill, T. J. 1907. Bitter rot of apples: Botanical investigations. Pages 554-615 in: Univ. Ill. Agric. Exp. Stn. Bull. No. 118.

Callahan, B. J., McMurdie, P. J., Rosen, M. J., Han, A. W., Johnson, A. J. A., and Holmes, S. P. 2016. DADA2: High-resolution sample inference from Illumina amplicon data. Nat. Methods 13:581-583.

Culumber, C. M., Reeve, J. R., Black, B. L., Ransom, C. V., and Alston, D. G. 2019. Organic orchard floor management impact on soil quality indicators: Nutrient fluxes, microbial biomass and activity. Nutr. Cycl. Agroecosyst. 115:101-115.

Damm, U., Cannon, P. F., Woudenberg, J. H. C., and Crous, P. W. 2012. The Colletotrichum acutatum species complex. Stud. Mycol. 73:37-113.

Debode, J., Van Hemelrijck, W., Baeyen, S., Creemers, P., Heungens, K., and Maes, M. 2009. Quantitative detection and monitoring of Colletotrichum acutatum in strawberry leaves using real-time PCR. Plant Pathol. 58:504-514.

De Mendiburu, F. 2009. Una herramienta de analisis estadistico para la investigacion agricola. Thesis, Universidad Nacional de Ingeniería.

Doores, S. 1983. The microbiology of apples and apple products. Crit. Rev. Food Sci. Nutr. 19:133-149.

Dowling, M. E., Peres, N. N. A., Villani, S. M., and Schnabel, G. 2020. Managing Colletotrichum on fruit crops: A "complex" challenge. Plant Dis. 104:2301-2316.

Droby, S., Wisniewski, M., Macarisin, D., and Wilson, C. 2009. Twenty years of postharvest biocontrol research: Is it time for a new paradigm? Postharvest Biol. Technol. 52:137-145. 
Eastburn, D. M., and Gubler, W. D. 1990. Strawberry anthracnose: Detection and survival of Colletotrichum acutatum in soil. Plant Dis. 74:161-163.

Eastburn, D. M., and Gubler, W. D. 1992. Effects of soil moisture and temperature on the survival of Colletotrichum acutatum. Plant Dis. 76: 841-842.

Ferree, D. C., and Warrington, I. J., eds. 2003. Apples: Botany, Production and Uses. CABI, Wallingford, U.K.

Francioli, D., Van Rijssel, S. Q., and Van Ruijven, J. 2021. Plant functional group drives the community structure of saprophytic fungi in a grassland biodiversity experiment. Plant Soil 461:91-105.

Freeman, S., Shalev, Z., and Katan, J. 2002. Survival in soil of Colletotrichum acutatum and C. gloeosporioides pathogenic on strawberry. Plant Dis. 86:965-970.

Gardes, M., and Bruns, T. D. 1993. ITS primers with enhanced specificity for basidiomycetes, application to the identification of mycorrihiza and rusts. Mol. Ecol. 2:113-118.

Kang, B.-K., Kim, J.-H., Lee, K.-H., Lim, S.-C., Ji, J.-J., Lee, J.-W., and Kim, H.-T. 2009. Effects of temperature and moisture on the survival of Colletotrichum acutatum, the causal agent of pepper anthracnose in soil and pepper fruit debris. Plant Pathol. J. 25:128-135.

Lahti, L., Shetty, S., and Blake, T. 2017. Tools for microbiome analysis in R. Microbiome Package Version 0.99.88. https:/github.com/microbiome/ microbiome

Martin, K. J., and Rygiewicz, P. T. 2005. Fungal-specific PCR primers developed for analysis of the ITS region of environmental DNA extracts. BMC Microbiol. 5:28.

Martin, P. L., Krawczyk, T., Khodadadi, F., Aćimović, S. G., and Peter, K. A. 2021. Bitter rot of apple in the Mid-Atlantic US: Causal species and evaluation of the impacts of regional weather patterns and cultivar susceptibility. Phytopathology 111:966-981.

Martin, P. L., and Peter, K. A. 2021. Quantification of Colletotrichum fioriniae in orchards and deciduous forests indicates it is primarily a leaf endophyte. Phytopathology 111:333-344.

McMurdie, P. J., and Holmes, S. 2013. Phyloseq: An R package for reproducible interactive analysis and graphics of microbiome census data. PLoS One 8:e61217.

Nguyen, D., Boberg, J., Ihrmark, K., Stenström, E., and Stenlid, J. 2016. Do foliar fungal communities of Norway spruce shift along a tree species diversity gradient in mature European forests? Fungal Ecol. 23:97-108.

NIH. 2021. Why do I see square brackets around some organism names in the NCBI Taxonomy database? https://support.nlm.nih.gov/knowledgebase/ article/KA-03379/en-us

Oksanen, J., Blanchet, F. G., Friendly, M., Kindt, R., Legendre, P., McGlinn, D., Minchin, P. R., O’Hara, R. B., Simpson, G. L., Solymos, P., Stevens, M. H. H., Szoecs, E., and Wagner, H. 2020. vegan: Community Ecology
Package Version 2.5-7. https://cran.r-project.org/web/packages/vegan/ index.html

Osono, T. 2006. Role of phyllosphere fungi of forest trees in the development of decomposer fungal communities and decomposition processes of leaf litter. Can. J. Microbiol. 52:701-716.

Parikka, P., and Lemmetty, A. 2009. Colletotrichum acutatum: Survival in plant debris and infection of some weeds and cultivated plants. Acta Hortic. 842:307-310.

Parikka, P., Lemmetty, A., and Pääskynkivi, E. 2006. Survival of Colletotrichum acutatum in dead plant material and soil in Finland. Acta Hortic. 708:131-134.

Penn State University Extension. 2020. Penn State Tree Fruit Production Guide, 2020-2021 ed. R. Crassweller, ed. Penn State University, University Park, PA, U.S.A.

Peres, N., Timmer, L. W., Adaskaveg, J. E., and Correll, J. C. 2005. Lifestyles of Colletotrichum acutatum. Plant Dis. 89:784-796.

R Core Team. 2021. R: A Language and Environment for Statistical Computing. R Foundation for Statistical Computing, Vienna, Austria.

Riedo, J., Wettstein, F. E., Rösch, A., Herzog, C., Banerjee, S., Büchi, L., Charles, R., Wächter, D., Martin-Laurent, F., Bucheli, T. D., Walder, F., and van der Heijden, M. G. A. 2021. Widespread Occurrence of pesticides in organically managed agricultural soils-The ghost of a conventional agricultural past? Environ. Sci. Technol. 55:2919-2928.

Rivers, A. R., Weber, K. C., Gardner, T. G., Liu, S., and Armstrong, S. D. 2018. ITSxpress: Software to rapidly trim internally transcribed spacer sequences with quality scores for marker gene analysis. F1000 Res. 7:1418.

Rosenberger, D. A., and Cox, K. 2016. Preventing bitter rot in apples. Scaffolds Fruit J. 25:1-4.

Sutton, T. B., Aldwinckle, H. S., Agnello, A. M., and Walgenbach, J. F., eds. 2014. Compendium of Apple and Pear Diseases and Pests, 2nd ed. American Phytopathological Society, St. Paul, MN, U.S.A.

Tutua, S. S., Goh, K. M., and Daly, M. J. 2002. Decomposition and nitrogen release of understorey plant residues in biological and integrated apple orchards under field conditions in New Zealand. Biol. Fertil. Soils 35: 277-287.

Ureña-Padilla, A. R., Mitchell, D. J., and Legard, D. E. 2001. Oversummer survival of inoculum for Colletotrichum crown rot in buried strawberry crown tissue. Plant Dis. 85:750-754.

USDA-NASS. 2018. Quick Stats. United States Department of Agriculture-National Agricultural Statistics Service. https:/quickstats. nass.usda.gov/results/8FF4A011-6FF8-3828-B329-FBD2787BED1C

Vořísková, J., and Baldrian, P. 2013. Fungal community on decomposing leaf litter undergoes rapid successional changes. ISME J. 7:477-486.

Weir, B. S., Johnston, P. R., and Damm, U. 2012. The Colletotrichum gloeosporioides species complex. Stud. Mycol. 73:115-180. 